\title{
UMA EXPERIÊNCIA DE FORMACÇÃO DE PESQUISADORES JUNIORES: DISCURSOS DO SUJEITO COLETIVO SOBRE A VIOLÊNCIA CONTRA A CRIANÇA
}

\section{AN EXPERIMENT FORMING JUNIOR RESEARCHERS: DISCURSE OF THE COLLECTIVE SUBJECT, ON VIOLENCE AGAINST CHILDREN}

\author{
Fernando Lefevre* \\ Ana Maria Cavalcanti Lefèvre ** \\ Evangelina Fernandes *** \\ Dulce Helena Cazzuni ${ }^{\dagger}$ \\ Neusa Guaraciaba dos Santos Oliveira ${ }^{\dagger+}$ \\ Ivany Yara de Medeiros ${ }^{\dagger+}$ \\ Grupo de alunos do projeto fonmação cidadã
}

Lefèvre F, e cols. Uma experiência de formação de pesquisadores júniores: discursos do sujeito coletivo sobre a violência contra a criança. Rev Bras Cresc Deseav Hum 2004; 14(3):67-78.

\begin{abstract}
Resumo: O presente artigo relata os resultados de uma experiência de fonmação de pesquisadores juniores, no quadro de uma parceria do Programa Bolsa Trabalho entre a Prefeitura de São Paulo, através da Secretaria Municipal do Desenvolvimento, Trabalho e Solidariedade e a Faculdade de Saúde Pública da USP. Os adolescentes de 16 a 20 anos inscritos no Programa Bolsa Trabalho que participam deste projeto mostraram-se capazes de adquirir as habilidades necessarias para se habilitarem profissionalmente como pesquisadores juniores, o que deve possibilitar o incremento da empregabilidade destes jovens. Para atingir estes resultados foi necessário desenvolver estratégias pedagógicas dinamicas que, usando de situações concretas e da corporiedade, dessem conta das defasagens próprias deste tipo de população.
\end{abstract}

Palavras Chave: Adolescentes; Pesquisa; Defasagens; Capital cultural; Estratégias pedagógicas.

\section{INTRODUÇÃO}

A capital paulista reúne grandezas de toda ordem. Tida como o maior centro produtivo $\wedge$ da América Latina, combina perversamente a opulência com a miséria. São mais de dez milhões de habitantes, com mais de um milhão de desempregados, cerca de dois milhões e meio de habitantes vivendo abaixo da linha de po^breza extrema, 1,47 salários mínimos mensais ${ }^{1}$ e quase seiscentos mil chefes de família cuja renda não chega a um salário mínimo e meio por mes. A esse contingente da população se reserva a falta de oportunidades, precária qualidade de vida e fragilidade no viver a cidadania.

Para o enfrentamento dessa realidade e buscando romper esse ciclo estrutural através da inclusão social, combate ao desemprego e desigualdade, a partir de 2001, a Prefeitura de São Paulo - PMSP, por meio da Secretaria do Desenvolvimento, Trabalho e Solidariedade SDTS implantou um conjunto articulado de nove progra-

\footnotetext{
* $\quad$ Professor Titular da Faculdade de Saúde Pública da USP.

** Professora Comissionada da Secretana Municipal da Saúde junto à Faculdade de Saúde Pública da USP.

*** Assessora técnica da Secretaria Municipal do Desenvolvimento, Trabalho e Solidanedade.

$\dagger$ Coordenadora do Programa Bolsa Trabalho da Secretana Municipal do Desenvolvimento, Trabalho e Solidanedade.

†† Doutora em Psicologia pelo Instituto de Psicologia da USP, Departamento de Psicologia Expenmental.

†† Mestranda no Departamento de Prática da Faculdade de Saúde Pública da USP.

* Nota dos autores, página 87
} 
mas que visam a geração de renda, a garantia de ocupação, a ampliação da qualidade de vida e a cidadania entre os paulistanos².

São três eixos programáticos: os redistributivos, os emancipatórios e os de desenvolvimento local ${ }^{3}$.

Para o presente trabalho, vamos nos ater ao primeiro eixo, relativo aos programas redistributivos, que são os que complementam a renda das famílias, para que superem a linha de pobreza. Neste eixo focalizaremos o Programa Bolsa Trabalho - PBT que caracteriza o atendimento de jovens de baixa renda, desempregados entre 16 e 29 anos de idade. Busca-se nele garantir temporariamente, a renda, associada à ampliação da escolaridade e ao envolvimento com atividades comunitárias e ocupacionais.

Com alternativas de atendimento diferenciado a perfis distintos, o PBT reune: Bolsa Trabalho Renda, Bolsa Trabalho Cursinho, Bolsa Trabalho Estágio e Bolsa Trabalho Emprego.

\section{Programa bolsa trabalho renda}

Cidade de tantos contrastes, na paulistana, com seus 96 distritos ${ }^{4}$, verificam-se grandes diferenças de renda, bem-estar, contrastes geográficos e extensa área territorial. Observandose os valores do Índice de Desenvolvimento Humano, IDH 2000, percebe-se que 38 dos distritos estão situados na região de Muito Baixo Desenvolvimento Humano ${ }^{1}$. Estudo realizado pela Fundação SEADE5, utilizando como metodologia o cálculo das variáveis: taxa de crescimento populacional; concentração de jovens entre 15 e 19 anos, taxa de homicídio por 100 habitantes, mães com idade entre 14 e 17 anos, valor de rendimento do chefe de família e quantidade de adolescentes que não freqüentam escolas, resultou no Índice de Vulnerabilidade Juvenil - IVJ ${ }^{5}$ com o qual mapeam-se na cidade locais de maior vulnerabilidade ao crime.

Através desse índice foi possível estimar que 336,1 mil adolescentes de 15 a 19 anos na cidade de São Paulo estão cotidianamente expostos a situações de vulnerabilidade social, convivendo frente a frente com a violência. Associando-se a esses indicadores o nível de emprego, implementou-se o atendimento aos beneficiários em todo município, ordenando-o seqüencialmente, a partir dos distritos de maior exclusão social. De 2001 a 2004 foram atendidos 63.471 jovens pelo Bolsa Trabalho, nos 96 distritos da cidade de São Paulo.

O Programa Bolsa Trabalho foi criado através da Lei $n^{\circ} 13.163$, de 05/07/2001, regulamentada pelo Decreto $n^{\circ} 40.845$, de 11/07/2001, com vários objetivos: oferecer meios para que os jo- vens de baixa renda pudessem continuar vinculados à rede escolar; proporcionar aos beneficiários uma capacitação adicional - não necessariamente dirigida ao mercado de trabalho, embora os cursos criem condições mais favoráveis para tanto; potencializar a integração de jovens em seus bairros, através do desenvolvimento de atividades comunitárias e do (rã) conhecimento dos distritos onde residem e melhorar as condições de vida dos jovens e de seu grupo familiar. Ao lado do fortalecimento do vínculo com a escola, o Bolsa Trabalho também busca assegurar que, na ausência de vagas no mercado de trabalho, os jovens não recorram a estratégias precárias de sobrevivência. O objetivo é retirar parte do peso que recai sobre o jovem que, muitas vezes. deve complementar renda familiar com "bicos", interrompendo sua trajetória escolar.

O alvo do Programa Bolsa Trabalho Renda é o jovem de dezesseis a vinte anos de idade que estude em escola pública (ou tenha concluído o ensino médio), não exerça atividade remunerada ou esteja desempregado, não possua rendimentos próprios, pertença à família de baixa renda (renda per capta igual ou inferior a meio salário mínimo mensal) e com ela resida no município de São Paulo há mais de dois anos. O beneficiário que deve manter freqüência igual ou superior a $85 \%$ (oitenta e cinco) nas atividades comunitárias ou de capacitação adicional, recebe um auxilio pecuniário, em valor fixado a $45 \%$ (quarenta e cinco) do salário mínimo nacional, além de seguro de vida coletivo e atendimento de despesas de deslocamento para a realização das atividades.

A metodologia utilizada para a capacitação dos jovens atendidos pelo Programa divide-se em dois grupos: o primeiro denominado módulo básico, de formação cidadã, e o segundo, denominado especifico, focado na capacitação ocupacional e na aprendizagem de utilidade coletiva e comunitária. O módulo básico de formação cidadã tem como objetivo o resgate da identidade e elevação da autoestima, para que os beneficiários se reconheçam como sujeitos e busquem alternativas coletivas de superação da vulnerabilidade social.

Os parâmetros metodológicos de concentração para a elaboração de projetos para o módulo específico foram desenvolvidos pela SDTS, juntamente com a parceira do projeto levando em conta áreas de capacitação que poderiam proporcionar ações voltadas para a geração de ocupação e renda - prioritariamente visando autonomização - para o mercado de trabalho, para a cultura do empreendedorismo e cooperativismo solidário e para atividades de aprendizagem em atividades de utilidade coletiva e comunitárias. 


\section{O Projeto de Formação de Pesquisadores Juniores}

No quadro do módulo especifico do Projeto Formação Cidadã, julgou-se que caberia um Projeto de Formação de Pesquisadores Juniores; tal projeto foi apresentado às instâncias competentes na PMSP/SDTS e lá aprovado. gerais:

O referido projeto linha como objetivos

- Com base em temas ligados à questão do trabalho na sociedade brasileira atual, lá ar os alunos a buscar o desenvolvimento das competências ligadas à pesquisa social aplicada a projetos que tenham por base resultados de pesquisa;

- Pemmitir a busca de conhecimento endógeno e exógeno do grupo enquanto categoria social; Seus objetivos especificas eram:

§ Apreensão de noções de metodologia cientifica e pesquisa social;

$\S$ Abordagem dos principais tipos de pesquisa social existentes;

§ Contato prático com a especificidade da relação pesquisador/pesquisado;

$\S$ Oportunidade de treinamento teóricoprático com a metodologia do Discurso do Sujeito Coletivo - DSC ${ }^{6}$.

O projeto previa 200 horas de curso envolvendo quatro grandes blocos:

- pesquisa como conhecimento; redigindo um projeto de pesquisa; desenvolvendo uma pesquisa;

- aplicando os resultados da pesquisa.

O presente artigo refere-se a um momento do primeiro bloco onde, a título de exercício, pediu-se aos alunos que realizassem uma pequena pesquisa.

\section{MÉTODOS}

\section{Procedimentos}

Fazendo parte do primeiro bloco, que tinha como tema a pesquisa como forma de conhecimento os alunos foram instados a realizar uma pesquisa. Para a escolha do tema foram divididos em quatro grupos e cada grupo propôs a relação de temas com os quais gostaria de trabalhar.

Os temas escolhidos tiveram que ser reduzidos a dois e para isso houve discussão em plenária, tendo sido escolhidos: violência contra a criança e violência contra a mulher.

杫 O formulário completo encontra-se no anexo 1.
Em seguida, em grupos, os alunos foram instados a redigir duas questões, que foram discutidas em plenária e aperfeiçoadas.

As questões finais selecionadas foram:

1. Na sua opinião o que leva um pai a espancar uma criança?

2. Na sua opinião o que leva um homem a praticar um ato de violência contra uma mulher?

Decidiu-se, também, como preconizado pela metodologia adotada, pela coleta de alguns dados cadastrais a respeito dos sujeitos entrevistados. Essa foi baseada na influência e relevância que certas características demográficas poderiam ter no discurso emitido pelo sujeito entrevistado. Após uma ampla discussão o grupo selecionou a coleta dos seguintes dados: sexo, idade e escolaridade ${ }^{11}$.

\section{RESULTADOS}

As duas questões escolhidas foram objeto de entrevistas, realizadas pelos alunos com 21 indivíduos, no bairro da Casa Verde, São Paulo.

Apresentaremos aqui, por uma questão de espaço, apenas os resultados quantitativos e qualitativos referentes à questão 1.

Descrição da população estudada

Quadro 1. Distribuição de freqüência por sexo da população estudada - casa verde 2004

\begin{tabular}{|c|c|}
\hline SEXO & FREQUÊNCIA \\
\hline MASCULINO & 6 \\
\hline FEMININO & 15 \\
\hline TOTAL & 21 \\
\hline
\end{tabular}

Quadro 2. Distribuição de frequência por idade da população estudada-casa verde 2004

\begin{tabular}{|c|c|}
\hline FAIXA ETÁRIA & FREQUÊNCIA \\
\hline $10-19$ & 3 \\
\hline $20-29$ & 12 \\
\hline $30-39$ & 4 \\
\hline $40 \mathrm{E}+$ & 2 \\
\hline TOTAL & 21 \\
\hline
\end{tabular}

Quadro 3. Distribuição de frequência por escolaridade da população estudada 2004

\begin{tabular}{|l|c|}
\hline ESCOLARIDADE & FREQUENCIA \\
\hline S/ESCOLARIDADE & 0 \\
\hline $1^{\circ} \mathrm{GI}$ & 2 \\
\hline $\mathbf{1}^{\circ} \mathrm{GC}$ & 0 \\
\hline $2^{\circ} \mathrm{GI}$ & 7 \\
\hline $2^{\circ} \mathrm{GC}$ & 9 \\
\hline $3^{\circ} \mathrm{GI}$ & 3 \\
\hline $3^{\circ} \mathrm{GC}$ & 0 \\
\hline TOTAL & 21 \\
\hline
\end{tabular}


- Resultados intermediários

No processamento de dados da metodologia do DSC ${ }^{6}$ a primeira operação consiste na transcrição literal de cada uma das respostas a cada uma das questões da pesquisa. A segunda operação consiste na seleção das Expressões Chave de cada uma das respostas, na identificação e nomeação das Idéias Centrais ligadas a estas Expressões Chave.

O quadro que descreve esta segunda operação, realizada em plenária com os alunos, é apresentado no Anexo 2. Resultados finais

Os resultados finais serão aqui apresenta- dos, inicialmente os qualitativos e em seguida os quantitativos

Resultados qualitativos

Os quadros que se apresenta abaixo descrevem, no título, as Categorias, ou seja, as Idéias Centrais-Síntese, que reunem em si cada uma das Idéias Centrais semelhantes encontradas nos depoimentos; no lado esquerdo do Quadro figuram as Expressões Chave de cada um dos depoimentos enquadrados na Categoria; no lado direito figura o Discurso do Sujeito Coletivo propriamente dito, que é reunião das Expressões Chave na forma de um discurso único.

Categoria $\mathrm{A}$ - A alcoolismo e drogas

\begin{tabular}{|c|c|}
\hline $\begin{array}{l}\text { Suj.1.1 idéia } O \text { alcoolismo, a droga,... } \\
\text { Suj.5-2a idéia ou se ele usar qualquer tipo } \\
\text { de droga, mesmo sendo o alcoolismo. } \\
\text { Suj6.2a idéia uso de bebidas alcoólicas e } \\
\text { também o uso de drogas... } \\
\text { Suj8.1a idéia pai ou uma mãe que utiliza } \\
\text { bebidas alcoolicas ou drogas } \\
\text { Suj9. } 2 \text { a idéia droga e álcool... } \\
\text { Suj12. } 2 \text { a idéia } O \text { alcoolismo e as drogas } \\
\text { fazem com que os pais se alteram dentro } \\
\text { de casa... } \\
\text { Suj14...quando ele chega embriagado em } \\
\text { casa ou até drogado } \\
\text { Suj19.2a idéia drogas se for dependente } \\
\text { delas } \\
\text { Suj.20...quando um pai tem problemas com } \\
\text { a bebida e as drogas. Ai ele se torna uma } \\
\text { pessoa agressiva, batendo no seu filho.. }\end{array}$ & $\begin{array}{l}\text { DSC } \\
\text { É o alcoolismo, a droga. } \\
\text { Quando o pai ou a mãe utilizam } \\
\text { bebidas alcoólicas ou drogas e } \\
\text { chegam em casa embriagados ou até } \\
\text { drogados, eles se alteram, tornando- } \\
\text { se pessoas agressivas e batendo em } \\
\text { seus filhos. }\end{array}$ \\
\hline
\end{tabular}

Categoria B - pais violentos

\begin{tabular}{|c|c|}
\hline $\begin{array}{l}\text { uj3. também } 2^{a} \text { idéia existe pessoas com } \\
\text { rios problemas que não tem noção de sua } \\
\text { iolência ... quando adverte uma criança } \\
\text { caba se descontrolando gerando o } \\
\text { spancamento. } \\
\text { uj5.1a idéia ser violento... não precisa de } \\
\text { otivos } \\
\text { uj6.3a idéia as vezes também pelo próprio } \\
\text { osto de simplesmente bater. Ele gosta do que } \\
\text { az. } \\
\text { uj21. } 3 \text { a idéia ... Esse comportamento revela } \\
\text { m caráter violento, e ao mesmo tempo, } \\
\text { ovarde do agressor... }\end{array}$ & $\begin{array}{l}\text { DSC } \\
\text { Existem pessoas com sérios problemas, } \\
\text { que não tem noção de sua violência: } \\
\text { quando advertem uma criança acaba se } \\
\text { descontrolando gerando } \\
\text { espancamento. } \\
\text { Esse comportamento revela um caráter } \\
\text { violento, e ao mesmo tempo, covarde } \\
\text { do agressor. } \\
\text { As vezes também pelo próprio gosto de } \\
\text { simplesmente bater:ele gosta do que } \\
\text { faz, não precisa de motivos. }\end{array}$ \\
\hline
\end{tabular}


Categoria C - problemas sociais

\begin{tabular}{|c|c|}
\hline $\begin{array}{l}\text { Suj3.Ia idéia é porque o pai ou a mãe têm algum } \\
\text { problema que não consegue resolver....Ia idéia Então a } \\
\text { pessoa acaba se descontrolando, sendo assim } \\
\text { acumulando o estresse do dia a dia com os seus } \\
\text { problemas la idéia e acha que descontando sua raiva em } \\
\text { pessoas que não tem nada a ver vai resolver, } \\
\text { Suj15. o "pai" está estressado com problemas } \\
\text { financeiros em casa, desempregado ... já é um motivo do } \\
\text { pai praticar o ato da violência. } \\
\text { Suj } 21.2 a \text { idéia ... quando o agressor sofre com } \\
\text { problemas econômicos... e não consegue resolver a } \\
\text { situação... gerando um...stress... que deposito toda sua } \\
\text { raiva nos filhos... que são figuras mais frágeis do seu } \\
\text { convivio }\end{array}$ & $\begin{array}{l}\text { DSC } \\
\text { É porque o pai ou a mãe está desempregado, } \\
\text { estressado, com problemas financeiros em casa; } \\
\text { então acaba se descontrolando, achando que já } \\
\text { é motivo para praticar o ato de violência, } \\
\text { descontando sua raiva em pessoas que não tem } \\
\text { nada a ver, seus filhos, as figuras mais frágeis } \\
\text { do seu convívio. }\end{array}$ \\
\hline
\end{tabular}

Categoria D - falta de diálogo

\begin{tabular}{|c|c|}
\hline $\begin{array}{l}\text { Suj1. } 2^{a} \text { idéia a falta de amor, carinho e } \\
\text { compreensão para com os filhos } \\
\text { Suj3.2a idéia espancam seus filhos por motivos } \\
\text { que podem ser resolvidos até mesmo com uma } \\
\text { conversa. } \\
\text { Suj8. mesmo } 2 \text { a ideía espancam seus filhos por } \\
\text { motivos que podem ser resolvidos até mesmo } \\
\text { com uma conversa } \\
\text { Suj9. a la ideía falta de paciência com os } \\
\text { problemas que acabam descontando numa } \\
\text { criança indefesa, criança inocente } \\
\text { Suj12. Ia ideía pai nervoso que não tem a } \\
\text { compreensão de entender uma criança. } \\
\text { Suj18. } 2^{a} \text { idéia falta é diálogo. }\end{array}$ & $\begin{array}{l}\text { DSC } \\
\text { É falta de amor, de carinho e } \\
\text { compreensão para com os filhos; } \\
\text { espancam seus filhos por motivos } \\
\text { que podem ser resolvidos até mesmo } \\
\text { com uma conversa. } \\
\text { Os pais nervosos, com falta de } \\
\text { paciência, que não tem compreensão } \\
\text { de entender uma criança acabam } \\
\text { descontando numa pessoa indefesa, } \\
\text { inocente. } \\
\text { O que falta é diálogo. }\end{array}$ \\
\hline
\end{tabular}

Categoria E-desobediência

Suj17. desobediência.

DSC

É porque a criança é desobediente

Categoria F - problemas pessoais

Suj2 ignorância, nervosismo, falta de maturidade

Suj4.esse pai é um insensivel, mal amado... esse pai não é capaz de coordenar sua própria vida e acaba descontando toda sua frustração naqueles que menos têm a ver com todos os seus problemas

Suj6. 1a idéia ele é um covarde e uma pessoa que não tem coragem de enfrentar os seus

\section{DSC}

É ignorância, nervosismo, falta de maturidade; esse pai é um insensível, mal amado, que não é capaz de coordenar sua própria vida e acaba descontando toda sua frustração naqueles que menos têm a ver com todos os seus problemas. 


\begin{tabular}{|c|c|}
\hline $\begin{array}{l}\text { óprios problemas, as suas próprias } \\
\text { cepção e desconta no seu filho ou na } \\
\text { iança todas as suas frustrações. } \\
\text { ¿j7.A falta de paciência...ele pode estar } \\
\text { rrvoso... desconta tudo na criança, a } \\
\text { tupidez. } \\
\text { ij10 ... mas espancar é só quem não tem } \\
\text { ração,é desalmada, não tem amor próprio. } \\
\text { ij11.A falta de amor que ele não deve ter } \\
\text { lo na infância e agora quer descontar nos } \\
\text { hos. } \\
\text { ij13.A loucura,... problema pessoal... acaba } \\
\text { scontando na criança,... } \\
\text { ij18.1a ideía pai fica nervoso por qualquer }\end{array}$ & $\begin{array}{l}\text { a ver com todos os seus problemas. } \\
\text { Ele é um covarde, uma pessoa que } \\
\text { não tem coragem de enfrentar os } \\
\text { seus próprios problemas, suas } \\
\text { decepções. } \\
\text { Também ele pode ter falta de } \\
\text { paciência, pode estar nervoso e } \\
\text { desconta tudo na criança: uma } \\
\text { estupidez. } \\
\text { Espancar uma criança é só quem } \\
\text { não tem coração, uma pessoa } \\
\text { desalmada, que não tem amor } \\
\text { próprio. } \\
\text { Pode ser também falta de amor que } \\
\text { ele não deve ter tido na infância ou } \\
\text { pode ter um trauma de infância e } \\
\text { agora quer descontar nos filhos, o } \\
\text { que seria para ele uma vingança. }\end{array}$ \\
\hline
\end{tabular}

- Resultados quantitativos

Embora. os próprios comentários dos entrevistados admitam que muitos pais ainda costumem espancar seus filhos, esse compor^latnento é condenado pela grande maiorias ao contrário do que acontecia no passado. A defesa aparece em apenas uma das respostas vindo a constituir a categoria E (3 \%) que justifica a violência no caso de desobediência por parte das crianças. Já o discurso mais veemente (Problemas Pessoais cate-

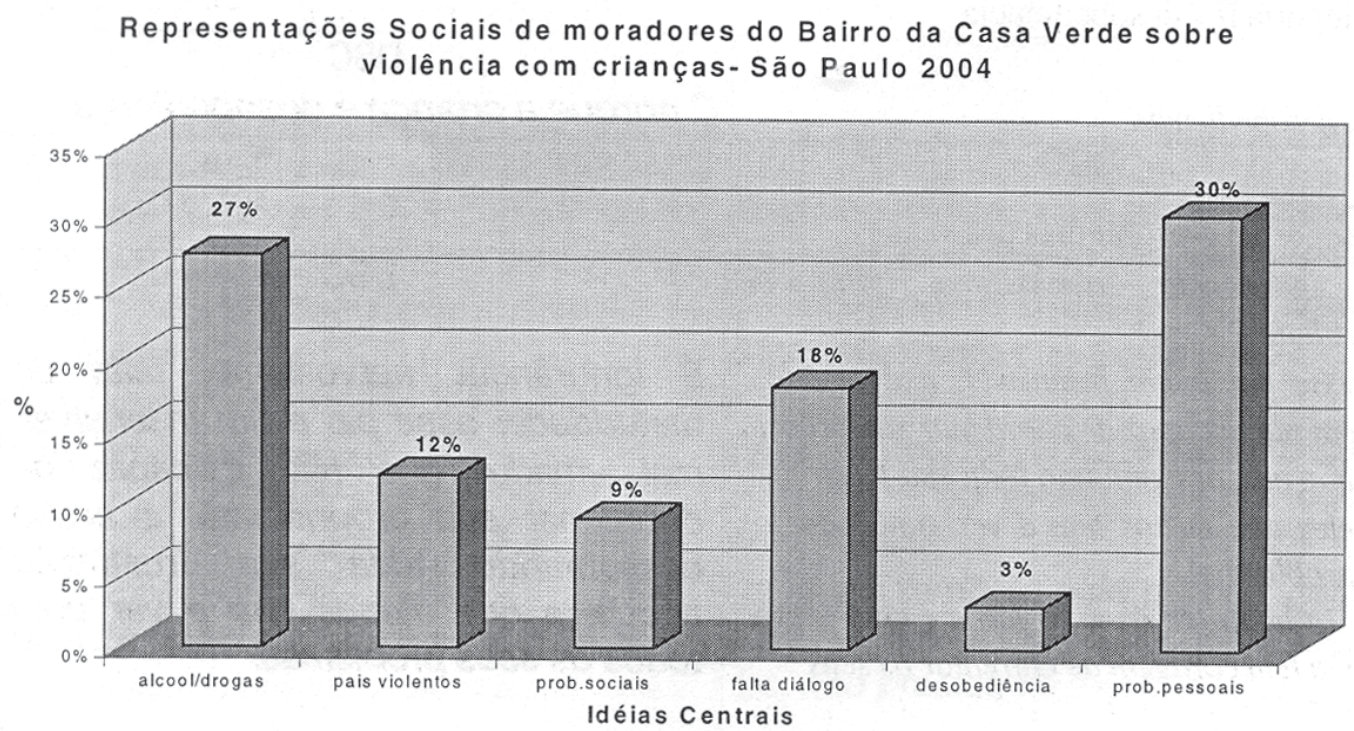


goria $\mathrm{F} 30 \%$ ) associa o espancamento às falhas dos pais que não sabem lidar com seus problemas pessoais e covardemente descontam suas frustrações nos mais fracos, seus filhos: "Também ele pode ter falta de paciência, pode estar nervoso e desconta tudo na criança: uma estupidez.”

Com o mesmo número de idéias, o discurso Alcoolismo e drogas - categoria A (27\%) associa o uso de drogas e o alcoolismo dos pais como a razão primordial da violência exercida contra seus filhos. É interessante observar o que poderíamos chamar de "pobreza" do DSC formado nessa categoria. Os entrevistados que aderem a essa idéia são extremamente sucintos ao dizer que os pais, por usarem drogas, espancam os filhos. Ou seja, o fato de usar drogas está, automaticamente, ligado à violência ou perda da razão. "Porque as vezes isto acontece mais quando um pai tem problemas com a bebida e as drogas. Aí ele se torna uma pessoa agressiva, batendo no seu filho e até mesmo machucando".

Em 18\% dos discursos (categoria D - Falta de diálogo) a falta de diálogo, associada à ausência de amor e compreensão por parte dos pais, é apontada como a razão dos pais virem a espancar seus filhos. Também nesse caso o ônus fica com os pais que "não têm compreensão de entender uma criança e acabam descontando numa pessoa indefesa, inocente.” Por último temos a categoria C - Problemas Sociais (9\%) culpabiliza a sociedade (falta de emprego, stress...) pela agressão do pai/mãe que "acaba se descontrolando, achando que já é motivo para praticar o ato de violência, descontando sua raiva em pessoas que não tem nada a ver.”

\section{DISCUSSÃO}

É possível formar pesquisadores juniores. O primeiro e mais significativo aspecto a salientar dos resultados é que os adolescentes do Projeto são capazes, se devidamente estimulados, de incorporar habilidades e informações que representam um passo importante para a sua habilitação como pesquisadores Jumores.

A incorporação destas habilidades concorrerá também, por certo, para incrementar a empregabilidade ${ }^{7}$ específica e geral destes alunos, uma vez que a função de pesquisados júnior tem condições de se configurar como uma ocupação emergente ${ }^{8} \mathrm{e}$ as habilidades cognitivas necessárias para tanto são evidentemente úteis para o desempenho de um sem número de outras ocupações.

Mas tão importante quanto constatar que estes adolescentes podem virar profissionais pesquisadores é entender que para que isso ocorra há que se mobilizar uma pedagogia específica.
De fato, o trabalho pedagógico com grupos de adolescentes requer sempre cuidados especiais em sua programação em virtude das características próprias desta faixa etárias ${ }^{9}$. Além disso, adolescentes que apresentem defasagens em decorrência de situações de desprivilegiamento social requerem cuidados adicionais o que significa um grande desafio para quem se proponha a essa tarefa.

De uma forma geral, sabe-se que os adolescentes carenciados, oriundos das classes desprivilegiadas, apresentam defasagens generalizadas quando comparados aos das classes mais favorecidas da nossa sociedade. Mas estas não seriam observadas somente em relação à baixa escolaridade ou em relação à aquisição de bens de consumo, mas acima de tudo afetam esses sujeitos de uma forma mais ampla, fenômeno que poderíamos denominar como capital cultural empobrecido.

Adicionadas a estas dificuldades esses adolescentes tinham experiência, tanto de vida como de escolaridade diferentes (apesar de todos estarem concluíndo o ensino médio) e apresentavam defasagens distintas entre eles. Se por um lado alguns manifestavam o interesse em seguir adiante em busca de um trabalho e de estudos que os distinguissem na sociedade, outros apresentavam uma postura de profundo desinteresse por qualquer atividade apresentada.

Além da heterogeneidade pôde-se observar que o déficit da atenção também se apresentava de forma muito persistente no grupo.

Estas características nos mobilizaram para a formulação de estratégias pedagógicas que permitissem o desenvolvimento de uma programação mais apropriada.

\section{Estratégias pedagógicas}

Assim sendo, para o desenvolvimento do projeto em pauta lançou-se mão de algumas estratégias pedagógicas:

\section{Ambiente enriquecido}

Considerou-se a imersão de alunos de nível médio, com presença de diferentes tipos de defasagens, em ambiente enriquecido de nível universitário, um dos fatores necessários para a aquisição sustentada de conhecimentos e habilidades.

O curso foi realizado na Faculdade de Saúde Pública da USP propiciando aos alunos um ambiente privilegiado para a realização de experiências pedagógicas enriquecedoras, pela facilidade de contato com professores e técnicos de diferentes áreas, bem como pela presença de equipamentos diferenciados, disponíveis na unidade onde ocorreu o curso. 
Contou-se com a participação de palestrantes especialistas em diversas áreas de interesse dos participantes, de forma que foi possível o estabelecimento de fortes referenciais teóricos para cada um dos temas abordados. O mesmo ocorreu com assuntos técnicos, uma vez que se contou com a participação de técnicos de som, de computação, artes gráficas e crônicas para discutir assuntos de natureza técnica com os alunos envolvidos no curso.

Foram também utilizados equipamentos diferenciados existentes na unidade: sala de micro computadores para a realização das pesquisas, sala de som, sala de vídeo. Contou-se para as aulas teóricas com data show, vídeo e retro-projetor.

Além disso, a Faculdade de Saúde Pública encontra-se localizada na Av. Dr. Arnaldo, ao lado da estação Clínicas do metrô de São Paulo, o que propiciou o acesso fácil dos alunos ao curso; além de oferecer um amplo jardim, com local para estudo ao ar livre e amplas salas com cadeiras e mesas reversíveis, bem como excelente biblioteca com várias salas de estudos para os alunos.

\section{Retomada do elo de ligação entre os estágios concretos e os estágios mais formais do pensamento}

Essa estratégia deve, a nosso ver, ser adotada (de forma persistente) em experiências pedagógicas programadas com grupos que apresentam defasagens.

Diz respeito à necessidade da passagem pelo estágio concreto do pensamento, em todas programações, como condição primária para a boa execução pelos alunos daquelas atividades fundamentadas e dependentes de uma base lógico formal do pensamento ${ }^{9,10,11}$.

Com efeito, o grupo de adolescentes deste projeto apresentava defasagens de todas as ordens:

- de natureza psicoafetiva como falta de atenção, hipercinesia, comportamento antissocial, agressividade, depressão, alheamento, entre outras;

- de natureza cognitiva e escolar, como dificuldades de leitura, compreensão de texto, de memorização, ortografia e déficits generalizados de informação;

- de natureza sociocultural, como falta de recursos para transporte, atenção dividida entre a atividade escolar e responsabilidades familiares, falta de acesso a bens de consumo e baixo capital cultural.

Além das defasagens acima descritas e até em razão delas, este grupo encontrava-se mais sujeito a intercorrências de várias ordens: agravos à saúde, em especial de natureza odontológica, abandono do lar pelos pais, acidentes, abortamentos, gravidez precoce, entre outros.
Assim, pareceu-nos fundamental o restabelecimento do elo entre o estágio concreto e o formal do pensamento como estratégia para que esses indivíduos pudessem superar, ainda que precariamente, essas defasagens.

O trabalho pedagógico que tem por base os processos grupais de reflexão pressupõe, como condição básica, que o adolescente em questão já tenha atingido a reversibilidad ${ }^{11}$ sobre estes temas, o que seria impraticável diante das suas condições precárias de vida.

Assim, é necessário propiciar a esses grupos várias experiências concretas programadas para superação de defasagens específicas, seguidas de sessões de discussão a respeito destas práticas, para que, gradualmente, seja estabelecida a capacidade de reflexão e de teorização sobre os temas propostaos.

O mesmo poderíamos colocar em relação à aquisição ou resgate de determinadas teorias. Falamos de resgate já que, freqüentemente, verificamos que os indivíduos já haviam adquirido ou entrado em contato com certos conhecimentos, os quais porém não se encontram integrados, ou seja, incorporados aos demais conhecimentos desse(s) sujeito(s).

A este respeito uma forma de resgate que nos pareceu adequada foi mobilizar o próprio corpo.

Poderíamos apresentar como exemplo desta estratégia a atividade por nós elaborada a respeito da teoria dos conjuntos, condição necessária para o entendimento pelos alunos da metodologia do Discurso do Sujeito Coletivo que lhes seria apresentada posteriormente.

Esta atividade consistiu no seguinte: os alunos foram inicialmente dispostos em círculo, cada um portando um limão, o qual se pediu que fosse demoradamente observado por cada aluno. A seguir os alunos se afastaram do círculo deixando ver os limões; perguntou-se então a eles o que aqueles limões em círculo significavam e um dos alunos respondeu que os mesmos representavam o conjunto dos alunos.

Assim, a teoria dos conjuntos foi discutida e restabelecida entre os alunos reorganizando-se os fragmentos de conhecimentos anteriormente adquiridos pelos mesmos por meio de atividades concretas com envolvimento da corporiedade.

A mesma técnica foi utilizada para a elaboração do conceito de gráfico. Utilizou-se os próprios alunos como forma de representação de suas idades, sendo eles mesmos colocados, por idade, em linhas desenhadas no chão. Assim, enquanto grupo, puderam visualizar a si mesmos, concretamente em um gráfico que apresentava a distribuição de freqüência dos alunos do curso, por idade. 


\section{CONSIDERAÇÕES FINAIS}

A opção pelo aprendizado de um método de pesquisa como o Discurso do Sujeito Coletivo baseou-se no pressuposto de que a complexidade da estratégia pedagógica e das atividades que teríamos que programar para o domínio do método se constituiria em um universo desafiador para os dois sujeitos envolvidos no processo: o grupo de monitores/instrutores e o de alunos.

O Discurso Do Sujeíto Coletivo é um método qualiquantitativo de pesquisa e por isso, para o seu aprendizado, o sujeito envolvido necessita de conhecimentos prévios tanto nas áreas da estatística e aritmética (ainda que, neste caso elementares) como nas áreas ditas sociais (teoria da representação, teorias sociais, psicologia social, marketing, história, entre outras). Trata-se, pois, de uma escolha metodológica complexa que requererá deste aluno conhecimentos prévios e uma grande capacidade de análise da realidade que o cerca.

Apresentava-se, pois, para os coordenadores do projeto, a necessidade de programar um grande rol de conhecimentos de entrada, como por exemplo que a noção de dominância de uma idéia depende do entendimento da noção de percentual, de teoria dos conjuntos, de interpretação de texto, de análise das representações sociais, etc.

Tratava-se também de entender que, para o indivíduo investigar o mundo que o cerca, é mais viável que isto seja feito através da escolha racional do estudo dos problemas que mais o afligem e da possibilidade de conhecer as diversas representações existentes em seu meio sobre o mesmo.

A reversibilidade será assim alcançada através da análise e do estudo do mundo que o cerca. Constatou-se também que a atividade de pesquisa oferece ao educando a oportunidade de vivenciar uma atividade organizada e metódica, que poderá auxiliá-lo em suas atividades de organização mental como um todo e também nas atividades de vida cotidiana.

Além disso, o Discurso do Sujeito Coletivo encontra-se materializado em um programa de software, o Qualiquantisoft, que permitiu que todos aprendessem a usá-lo por meio de ferramentas de informática, de inegável utilidade na vida prática destes indivíduos.

Todas estas escolhas nos pareceram mais propícias para o desenvolvimento e resgate das defasagens, precisamente, pelo aspecto desafiador (para os alunos) envolvido. Esta postura é contrária ao que se tem proposto para populações carenciadas, como trabalho com sucatas, realização de bordados, representações simplificadas através de desenho livre, etc que, acreditamos, estão na maior parte das vezes voltadas a ocupar este sujeito, mais do que a inseri-lo, criativamente, no universo que o cerca, além de estarem pressupondo que, justamente pelas suas defasagens, estes alunos precisam ser infantilizados para aprenderem, o que não apenas não é real como produz rebaixamento da auto estima dos envolvidos nestes processos.

\begin{abstract}
This article contains lhe results of an experiment exhibiting lhe develpmental process of Junior Researchers. This experiment was conducted in association with lhe Programa Bolsa e Trabalho, (Scholarship and Work Program), channeled through lhe Secretaria Municipal de Desenvolvimento, (Municipal Developing Department), Trabalho e Soledaridade (Work and Solidarit) and lhe Faculdade de Saude Publica (lhe School of Public Health) at lhe University of São Paulo (USP). Teenagers afina from 16 to 20 years old, who joined lhe programa Bolsa e Trabalho and this research experiment where capable of acquiring the skills necessary to behave professionally to become Junior Researchers, and thus improve the their employment chances in the future. To achieve these results, it was essential to come up with dynamic pedagogic strategies which, when using concrete and daily situations, were able to cope with the social handicaps of this part of the population.
\end{abstract}

Key-words: Adolescence. Research. Social Handicap. Cultural Capital. Peda ogic Strategies.

\section{REFERÊNCIAS}

1 Secretaria do Desenvolvimento Trabalho e Solidariedade - SDTS - Pobreza e violência no município de São Paulo. São Paulo. 2002.

2 Pochmann, M. (org.) Outra cidade é possível: alternativas de inclusão social em São Paulo: Cortez.2003.
4 Pochmann, M. (org) Desenvolvimento, trabalho e solidariedade: novos caminhos para a inclusão social. Ed. Cortcz.2002

4 Instituto Brasileiro de Geografia e Estatística IBGE>URL:http://www.ibge.gov.br>.[2Q04Set 17].

5 Fundação Sistema Estadual de Anàlise de Dados SEADE.<URL: httpp://www. seade. gov. br/produtos/prod-outrossitios htm: [2004Ag 28]. 
6 Lefevre F: Lefevre AMC. O Discurso do Sujeito Coletivo. Um novo enfoque em pesquisa qualitativa (Desdobramentos) . Caxias do Sul, Educs. 2003

7 Chiavenato I. Talento e empregabilidade. $<\mathrm{U}$ RL: http://www.chiavenato.com>. [2004 Set 17].

8 Projelo de Lei 3.534104 do Deputado Orlando Fantazzini. Regula a profissão de pesquisador e técnico de mercado, opinião e mídia e orga- niza os conselhos regionais e federal das categorias. <URL:http://www.sbpm.org.br/main.gov br> [2Q04Set 17]

9 Dolle J M. Para compreender Jean Piaget. Rio de Janeiro, Zahar 1978.

10 Boden M As idéias de Piaget. São Paulo, Cultrix, 1983.

11 Piaget J. Seis estudos de psicologia. Rio de Janeiro, Forense, 1972

\title{
NOTA DOS AUTORES
}

Este artigo baseou-se em pesquisa conjunta realizada pelos jovens benefíciános do Programa Bolsa Trabalho, da Secretaria do Desenvolvimento. Trabalho e Solidariedade da Prefeitura Municipal de São Paulo que cederam-na a titulo gratuito à RBCDH.

\section{Alunos:}

Helen Silvana Pereira da Silva: Andressa Emilia Verissimo Pereira: Magno César Campos Araújo de Oliveira; Angélica de Jesus Siqueira;Viviane Lopes Di Bert; Robson Silva de Moraes; Rodrigo Santiago; Almir Felipe; Ronaldo Felipe; Rafael Alves Pereira Soares; loana Vieira Rocha; Femanda da Silva; Danielle Filon Marques; Rodngo Gomes: Katia Guirlanda de Almeida: Ricardo Gomes Soares; Antonio Geilson Santiago dos Reis; Vanessa Cristina dos Santos; Danieli da Criz Silva; David Di Passi Macgado; Dayse Mayumi Kuba.

\author{
ANEXO 1 \\ Formulário \\ Eu sou..................................... Estou em um curso de pesquisa da USP e estamos fazendo uma pesquisa sobre \\ violência. \\ Vou fazer duas perguntas você responderia?
}

DADOS QUALITATIVOS

1. Na sua opinião o que leva um pai a espancar uma criança?

2.Na sua opinião o que leva um homem a praticar um ato de violência contra uma mulher?

\section{DADOS QUANTITATIVOS}

Eu necessito de alguns dados complementares. Você poderia me responder?

$\begin{aligned} & \text { Sexo: } \text { Masculino ( ) } \\ & \text { Feminino ( ) }\end{aligned}$

Idade:

Até que ano estudou? 


\section{ANEXO 2}

Pergunta: na sua opinião, o que leva um pai/mãe a espancar uma criança?

\begin{tabular}{|c|c|}
\hline Expressões- chave & Idéias Centrais \\
\hline $\begin{array}{l}1.1^{\circ} \text { idéiaO alcoolismo, a droga, } 2^{a} \text { idéia a falta de amor, carinho e compreensão para } \\
\text { com os fillhos. }\end{array}$ & $\begin{array}{l}\text { A- } 1^{\circ} \text { idéia - } \\
\text { Alcoolismo,droga } \\
D-2^{a} \text { idéia- falta de } \\
\text { amor,carinho e } \\
\text { compreensão com } \\
\text { filhos }\end{array}$ \\
\hline 2.Eu acho que é uma ignorância, nervosismo, falta de maturidade & $\begin{array}{l}\text { F-Ignorância, } \\
\text { nervosismo, falta de } \\
\text { maturidade }\end{array}$ \\
\hline $\begin{array}{l}\text { 3.Não que isso seja certo ou sirva como desculpa, mas eu acho que quando isso } \\
\text { acontecela idéia é porque o pai ou a mãe têm algum problema que não consegue } \\
\text { resolver, como o desemprego a má qualidade de vida e principalmente quando a } \\
\text { pessoa se deixa levar por pensamentos de inferioridade que para ela nada está ou dá } \\
\text { certo.Ia idéia Então a pessoa acaba se descontrolando, sendo assim acumulando o } \\
\text { estresse do dia a dia com os seus problemaslidéia la idéia e acha que descontando sua } \\
\text { raiva em pessoas que não tem nada a ver vai resolver, achando que tudo é motivo pra } \\
\text { bater. Mas também } 2 \text { a idéia existe pessoas com sérios problemas que não tem noça de } \\
\text { sua violência ao falar ou ao dar um tapa numa criança, ou seja, a pessoa ser violenta } \\
\text { que quando adverte uma criança acaba se descontrolando gerando o espancamento. }\end{array}$ & $\begin{array}{l}\text { C- } I^{a} \text { idéia-O pai ou } \\
\text { a mãe tem um } \\
\text { problema que não } \\
\text { consegue resolver } \\
\text { então acaba } \\
\text { descontando sua } \\
\text { raiva no filho. } \\
\text { B-2a idéia- pessoas } \\
\text { que não controlam } \\
\text { a própria violência }\end{array}$ \\
\hline $\begin{array}{l}\text { 4.Na minha opinião esse pai é um insensivel, mal amado e acaba descontando nos seus } \\
\text { filhos todos os problemas particulares, nas pessoas que não têm nada a ver com isso. } \\
\text { Para mim esse pai não é capaz de coordenar sua própria vida e acaba descontando } \\
\text { toda sua frustração naqueles que menos têm a ver com todos os seus problemas. }\end{array}$ & $\begin{array}{l}\text { F- Pai insensivel, } \\
\text { mal amado } \text { e } \\
\text { desconta os seus } \\
\text { problemas em quem } \\
\text { não tem nada a ver. }\end{array}$ \\
\hline $\begin{array}{l}\text { 5.Apenas o fato dele Ia idéia ser violento: eu acho que ele para bater em uma criança } \\
\text { não precisa de motivos; } 2 \text { a idéia ou se ele usar qualquer tipo de droga, mesmo sendo o } \\
\text { alcoolismo. }\end{array}$ & $\begin{array}{l}\text { B-1a idéia-ser } \\
\text { violento } \\
\text { A-2a idéia- usar } \\
\text { droga }\end{array}$ \\
\hline $\begin{array}{l}\text { 6.Na minha opinião um pai que espanca uma criança Ia idéia ele é um covarde e uma } \\
\text { pessoa que não tem coragem de enfrentar os seus próprios problemas, as suas próprias } \\
\text { decepça e desconta no seu filho ou na criança todas as suas frustrações.O que leva } \\
\text { ele a espancar uma criança é a covardia de enfrentar um homem na rua.Todo pai que } \\
\text { espanca un filho deveria ser espancando também. Ás vezes também ele se motiva no } \\
\text { espancamento pelo próprioza idéia uso de bebidas alcoólicas e também o uso de } \\
\text { drogas; } 3 \text { a idéia as vezes também pelo próprio gosto de simplesmente bater. Ele gosta } \\
\text { do que faz. }\end{array}$ & $\begin{array}{l}\text { F-Ia idéia- } \\
\text { covardia para } \\
\text { enfrentar os } \\
\text { problemas e } \\
\text { desconta na } \\
\text { criança. } \\
\text { A-2a idéia- uso de } \\
\text { bebidas alcoólicas e } \\
\text { drogas } \\
\text { B-3a idéia -gosta de } \\
\text { bater }\end{array}$ \\
\hline $\begin{array}{l}\text { 7.A falta de paciência com a criança porque ele pode estar nervoso com alguma coisa } \\
\text { e desconta tudo na criança, a estupidez. }\end{array}$ & $\begin{array}{l}\text { F- Falta de } \\
\text { paciência, } \\
\text { nervosismo, } \\
\text { estupidez e } \\
\text { desconto na } \\
\text { criança. }\end{array}$ \\
\hline $\begin{array}{l}\text { 8. As crianças hoje sofrem violência quando tem umla idéia pai ou uma mäe que utiliza } \\
\text { bebidas alcoólicas ou drogas. Às vezes até mesmo } 2 \text { a idéia espancam seus filhos por } \\
\text { motivos que podem ser resolvidos até mesmo com uma conversa. }\end{array}$ & $\begin{array}{l}\text { A-la idéia-uso de } \\
\text { bebida alcoólica ou } \\
\text { drogas. } \\
\text { D-2a idéia-falta de } \\
\text { diálogo. }\end{array}$ \\
\hline
\end{tabular}




\begin{tabular}{|c|c|}
\hline $\begin{array}{l}\text { 9.É a } 1^{a} \text { idéia falta de paciência com os problemas que acabam descontando } \\
\text { numa criança indefesa, criança inocente que apanha, é espancada e nem sabe } \\
\text { porque. Outros motivos da violência: } 2 \text { a idéia droga é álcool. }\end{array}$ & $\begin{array}{l}\text { D-1a idéia- falta } \\
\text { de paciência com } \\
\text { problemas } \quad \text { e } \\
\text { desconta } \\
\text { criança } \\
\text { A-2a idéia - droga } \\
\text { e álcool }\end{array}$ \\
\hline $\begin{array}{l}\text { I0.Muitos pais sabem que às vezes temos que dar umas palmadas, mas } \\
\text { espancar é só quem não tem coração,é desalmada, não tem amor próprio. }\end{array}$ & $\begin{array}{l}\text { F- Quem espanca } \\
\text { é quem não tem } \\
\text { sentimentos }\end{array}$ \\
\hline $\begin{array}{l}\text { 11.A falta de amor que ele não deve ter tido na infância e agora quer descontar } \\
\text { nos filhos. }\end{array}$ & $\begin{array}{l}\text { F- Falta de amor } \\
\text { na infância }\end{array}$ \\
\hline $\begin{array}{l}\text { I2.Um Ia idéia pai nervoso que não tem a compreensão de entender uma } \\
\text { criança. } 2 \text { a idéia } O \text { alcoolismo e as drogas fazem com que os pais se alteram } \\
\text { dentro de casa e acabam tendo este tipo de atitude. }\end{array}$ & $\begin{array}{l}\text { D- Ia idéia- pai } \\
\text { que não } \\
\text { compreende os } \\
\text { filhos } \\
\text { A-2a idéia- } \\
\text { alcoolismo e } \\
\text { drogas }\end{array}$ \\
\hline $\begin{array}{l}\text { 13.A loucura, pode até ser um problema pessoal e ai acaba descontando na } \\
\text { criança, espancando ela. }\end{array}$ & $\begin{array}{l}\text { F-Loucura e } \\
\text { problema pessoal }\end{array}$ \\
\hline $\begin{array}{l}\text { 14.Na minha opinião muitas vezes o pai espanca uma criança quando ele } \\
\text { chega embriagado em casa ou até drogado. }\end{array}$ & $\begin{array}{l}\text { A-Alcoolismo e } \\
\text { drogas }\end{array}$ \\
\hline $\begin{array}{l}\text { 15. Se a criança é pequena e desobediente e o "pai" está estressado com } \\
\text { problemas financeiros em casa, desempregado e com dívidas e a criança } \\
\text { apronta já é um motivo do pai praticar o ato da violência. }\end{array}$ & $\begin{array}{l}\text { C-Pai estressado, } \\
\text { desempregado } \\
\text { com problemas } \\
\text { financeiros }\end{array}$ \\
\hline $\begin{array}{l}\text { 16.Os pais devem conversar com os filhos e nâo espancar, é conversando que } \\
\text { se entende. }\end{array}$ & Excluída \\
\hline 17.De 0 a 13 anos é desobediência. & E-Desobediência \\
\hline $\begin{array}{l}\text { 18. Ela acha que o la idéia pai fica nervoso por qualquer motivo e acaba } \\
\text { descontando na criança e o que } 2^{a} \text { idéia falta é diálogo. }\end{array}$ & $\begin{array}{l}\text { F-1a idéia } \\
\text { nervosismo } \\
\text { D-2a idéia- falta } \\
\text { de diálogo }\end{array}$ \\
\hline 19.01a idéia- nervoso ou 2 a idéia drogas se for dependente delas. & $\begin{array}{l}\text { F-1a idéia- } \\
\text { nervosismo } \\
\text { A-2a idéia- } \\
\text { dependência de } \\
\text { drogas }\end{array}$ \\
\hline $\begin{array}{l}\text { 20.Olha, é dificil responder porque às vezes, nestes casos, é } \\
\text { complicado.Porque às vezes isto acontece mais quando um pai tem problemas } \\
\text { com a bebida e as drogas. Ai ele se torna uma pessoa agressiva, batendo no } \\
\text { seu filho e até mesmo machucando. }\end{array}$ & $\begin{array}{l}\text { A- Uso de bebidas } \\
\text { e drogas. }\end{array}$ \\
\hline $\begin{array}{l}\text { 2l.Na minha opinião, os motivos que levam as pessoas a agredirem uma } \\
\text { criança podem ser divididos em dois tipos: }{ }^{a} \text { idéia- problemas psicológicos } \\
\text { onde o agressor pode ter um trauma de infância que o leva, de uma forma } \\
\text { inconsciente a revidar a agressão sofrida em uma criança, o que seria para ele } \\
\text { uma vingança, esse é apenas um exemplo de desvio psicológico. Problemas } \\
\text { socioeconômicos, geralmente esse tipo de violência ocorre } 2^{a} \text { idéia quando o } \\
\text { agressor sofre com problemas econômicos entre outros e não consegue } \\
\text { resolver a situação gerando um estado de stress no mesmo que deposita toda a } \\
\text { sua raiva nos filhos ou esposa que são figuras mais frágeis do seu convivio. } 3^{a} \\
\text { idéia Esse comportamento revela um caráter violento e, ao mesmo tempo, } \\
\text { covarde do agressor, que na maioria dos casos não reconhece o problema que } \\
\text { possui. }\end{array}$ & $\begin{array}{l}\text { F-Problemas } \\
\text { pessoais } \\
\text { C-Problemas } \\
\text { sociais } \\
\text { B-Pais violentos }\end{array}$ \\
\hline
\end{tabular}

